\title{
Protective function of silicon deposition in Saccharina japonica sporophytes (Phaeophyceae)
}

\author{
Hiroyuki Mizuta • Hajime Yasui
}

Received: 28 September 2011 /Revised and accepted: 2 November 2011 /Published online: 18 November 2011

(C) The Author(s) 2011. This article is published with open access at Springerlink.com

\begin{abstract}
We investigated biogenic silica deposition in sporophytes of kelp, Saccharina japonica (Laminariaceae). Silicon content was measured in different sporophyte regions and there was a trend for the silicon content to increase longitudinally from the stipe-blade transition to apical regions. The transverse trend was for the content to be higher in the marginal region than in the medial region. The silicon content was also higher in the scar and sorus regions compared with the adjacent vegetative regions. High silicon content was detected in the margin of the disc and in the sorus region of cultured sporophyte discs. Moreover, rhodamine 123 staining suggested that silicon was deposited in the mouth of the marginal wound of the disc. Rhodamine 123 fluorescence was also detected in the paraphyses and mucilaginous caps of sori. These results suggest that silicon plays important roles in tissue protection and vegetative tissue wound healing. It is also suggested that silicon is required for the protection of reproductive tissues. We also discuss the physiological and ecological roles of biogenic silica deposition in kelp and its management in cultivated fields.
\end{abstract}

Keywords Kelp · Protection · Reproduction · Resistance . Silicon . Wound healing

H. Mizuta $(\bowtie)$

Laboratory of Aquaculture Genetics and Genomics,

Faculty of Fisheries Sciences, Hokkaido University,

Minato 3-1-1, Hakodate,

Hokkaido 041-8611, Japan

e-mail: mizuta@fish.hokudai.ac.jp

H. Yasui

Laboratory of Marine Industrial Science and Technology,

Faculty of Fisheries Sciences, Hokkaido University,

Minato 3-1-1, Hakodate,

Hokkaido 041-8611, Japan

\section{Introduction}

Silicon is known to be a nutritional requirement of a number of algae and higher plants (Lewin and Reimann 1966). Diatoms are representative algae requiring silicon for the formation of epithecae and hypthecae, and reproduction is often limited by the ambient silicon concentration of seawater. It has also been reported that silicon is accumulated in some green and brown algae (Parker 1969). The cell wall is suggested to be the chief localization site of silicon. Moore and Traquair (1976) reported that the green alga Cladophora glomerata requires silicon as a nutrient because it promotes growth of the algae; it is distributed in the cell wall. They also reported that algal growth was inhibited by germanium dioxide, which is a competitive inhibitor of silicon. Germanium dioxide also suppresses the growth of Laminaria (Tatewaki and Mizuno 1979; Markham and Hagmeier 1982; Shea and Chopin 2007), Fucus (McLachlan et al. 1971; Tatewaki and Mizuno 1979) and 10 other species of brown algae (Tatewaki and Mizuno 1979). Parker (1969) described that the low level of silicon detected was not necessarily insignificant. However, it is not known whether brown algae require silicon as a nutrient for growth.

All brown algae possess small amounts of silicon, including the order Laminariales which contains many industrially important species. For example, Ecklonia cava contains $23.9 \mu \mathrm{g} \mathrm{gDW}^{-1}$ in the blade and $13.35 \mu \mathrm{g} \mathrm{gDW}^{-1}$ in the stipe (Fu et al. 2000). The silicon contents of ashed Undaria pinnatifida, Ecklonia kurome and Saccharina japonica were reported as $0.11,0.056$ and 0.054 mass\%, respectively (Kohata et al. 2008). Thus, previous studies suggest that the silicon content is highly variable among different species. 
The role of silicon has been investigated in terrestrial plants (Currie and Perry 2007; Liang et al. 2007), where metal toxicity, salinity, drought and temperature stresses can be alleviated by silicon application (Liang et al. 2007). Yoshida et al. (1962) examined the role of silica deposition as a physical barrier in penetration and reduction of the susceptibility to enzymatic degradation by fungal pathogens. Although omission of silicon in the growth medium did not have any effect on the growth of brown algae, we predict that silicon has a role as a physical barrier in brown algae.

We focused on the role of silicon in the industrially important kelp, S. japonica. We initially compared the silicon content in the longitudinal and transverse regions of the thallus, and among scars, sori and the adjacent vegetative regions. We then investigated silicon deposition by culturing sporophyte discs. In this study, we further discuss the role of silicon in the management of $S$. japonica growth and reproduction.

\section{Materials and methods}

Five sporophytes of $S$. japonica (300-400 $\mathrm{cm}$ in length) were collected from a coastal area near Hakodate, Hokkaido, Japan in May and June 2011. A cork borer was used to remove discs (11.5 $\mathrm{mm}$ in diameter) along the median fasciae of sporophytes at 5, 100, 200,300 and $400 \mathrm{~cm}$ from the stipe-blade transition. In addition, discs were also collected from the centre and margin of the marginal region at 100, 200 and $300 \mathrm{~cm}$ from the transition of the sporophyte. In the basal part of the narrow marginal region, discs were collected only from the edge of the marginal region situated at $5 \mathrm{~cm}$ from the transition. We removed about $1 \mathrm{~mm}$ of the hardened part around the hole of the scar on the thallus and also a part of outer vegetative region with no wound. If the thallus had formed sori, we collected the sorus portions and adjacent non-sorus portions. All discs and segments were weighed and prepared before measuring the biogenic silicon content.

Analytical samples were washed with distilled water, wiped with a paper towel and placed in Oak Ridge centrifuge tubes $(10 \mathrm{~mL}$; Nalgene, USA) with $1 \mathrm{~mL}$ of $0.2 \mathrm{~N} \mathrm{NaOH}$. Samples were extracted at $100^{\circ} \mathrm{C}$ for $20 \mathrm{~min}$ and the tubes were centrifuged at $7,000 \times \mathrm{g}$ for $5 \mathrm{~min}$. Extracts were collected and neutralised with $200 \mu \mathrm{L}$ of $1 \mathrm{~N}$ $\mathrm{H}_{2} \mathrm{SO}_{4}$. The neutralised solution was diluted with distilled water and the resulting solution was analysed for dissolved reactive silicate using the acid molybdate method of Parsons et al. (1984). A calibration of reactive silicate concentrations was conducted using CSK standard solutions (Wako Chemicals, Osaka, Japan). The silicon content was expressed as $\mu \mathrm{g} \mathrm{g}^{-1}$ fresh weight.
Further sporophyte discs $(3 \mathrm{~cm}$ in diameter) were collected at 100-200 $\mathrm{cm}$ from the stipe-blade transition and used for culturing. Discs were cultured in a 1-L polyethylene terephthalate bottle with Provasoli's enriched seawater medium (Provasoli 1968) without vitamins and under aeration. The culture conditions were set at $10^{\circ} \mathrm{C}$, $60 \mu \mathrm{mol}$ photons $\mathrm{m}^{-2} \mathrm{~s}^{-1}$ (8-h light/16-h dark cycle). The seawater used for culturing contained $1.4 \mu \mathrm{M}$ silicate. Media were changed every week. After 1 month, the disc was collected and divided into two parts: the margin and the centre. The margin was cut $1 \mathrm{~mm}$ in width from the edge of the disc. The silicon content of these samples was analysed using the method described above. When discs formed sori, sori and the adjacent regions were sampled and analysed for their silicon content.

The silicon distribution was observed by staining with rhodamine 123 , which was previously used to visualise silica deposition in diatoms, demosponges and bacteria $(\mathrm{Li}$ et al. 1989; Brezeinski and Conley 1994; Müller et al. 2005, 2008). Sporophyte discs $(1.15-3 \mathrm{~cm}$ in diameter) were incubated in Provasoli's enriched seawater with $50 \mu \mathrm{g} \mathrm{mL}^{-1}$ of rhodamine 123 (Wako Chemicals, Japan) for 3 days. After incubation, the discs were removed and rinsed with sterilised seawater to remove surface rhodamine 123. Discs and their hand-cut sections were observed using a fluorescence microscope (AH2; Olympus, Japan) at an excitation wavelength of $380-490 \mathrm{~nm}$.

Data are expressed as means \pm standard deviation. Significant differences in the silicon content of discs and segments were tested using the one-tailed paired Student's $t$ test. The level of significance was set at $P<0.05$.

\section{Results}

Figure 1 shows the longitudinal and transverse silicon distribution in the $S$. japonica thallus. The silicon content $\left(9.6 \pm 4.7 \mu \mathrm{g} \mathrm{gFW}^{-1}\right)$ of the median fascia $300 \mathrm{~cm}$ from the stipe-blade transition was significantly higher than that of the basal median fascia $\left(2.6 \pm 0.6 \mu \mathrm{g} \mathrm{gFW}^{-1}\right)$. A similar trend was observed in the marginal region where the silicon content increased from the basal to apical regions. The transverse silicon content showed a trend to increase from the median fascia to the edge of the marginal region. The silicon content in the edges of the marginal regions $200 \mathrm{~cm}$ from the stipe-blade transitions $\left(26.0 \pm 14.0 \mu \mathrm{g} \mathrm{gFW}^{-1}\right)$ was seven times higher than that in the median fasciae $(3.65 \pm$ $\left.1.40 \mu \mathrm{g} \mathrm{gFW}^{-1}\right)$. The mean silicon content in the stipe was $7.25 \pm 2.45 \mu \mathrm{g} \mathrm{gFW}^{-1}$.

The silicon contents of scars, sori and the adjacent vegetative region with no wound are shown in Fig. 2. The silicon content fluctuated considerably among scar and sorus samples. The variation in silicon content among 


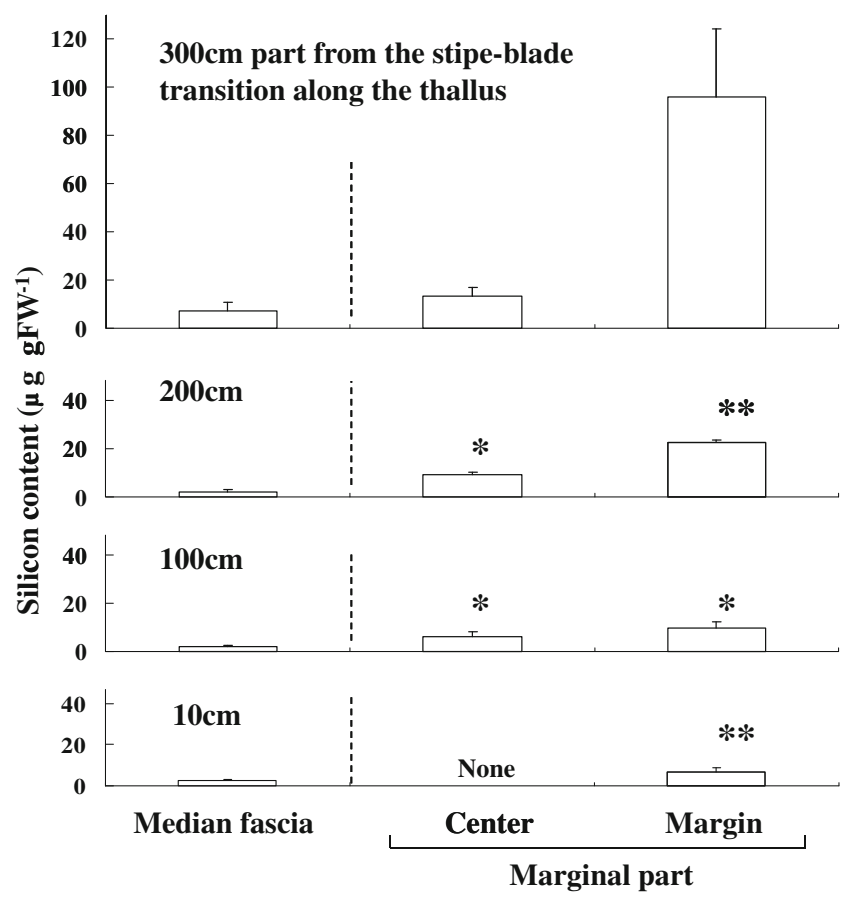

Fig. 1 Longitudinal and transverse distribution of silicon content in Saccharina japonica sporophytes collected in June 2011. Data represent means $\pm \mathrm{SD}(n=5)$. Asterisks indicate significant differences at $P<0.05$ and $P<0.01$

samples appeared to be related to the sampling sites on sporophytes, i.e. it was depended on the longitudinal and transverse distribution of the silicon content (Fig. 1). However, we identified consistent trends between scars and the adjacent regions and between sori and the adjacent regions. The silicon content was higher in scars (Fig. 2a) and sori (Fig. 2b) compared with the adjacent vegetative regions.

The high silicon contents in the wounded regions and sori were clearly demonstrated in sporophyte discs cultured in the laboratory (Fig. 3). The silicon content in the wounded regions located in the marginal parts of disc was approximately $16.1 \mathrm{\mu g} \mathrm{gFW}^{-1}$, which was approximately 1.6 times higher than that in the central vegetative region of discs $\left(10.0 \mu \mathrm{g} \mathrm{gFW}^{-1}\right)$ (Fig. 3a). The silicon content of the sorus region was $6.13 \mu \mathrm{g} \mathrm{gFW}{ }^{-1}$, which was 1.8 times higher than that in the adjacent vegetative regions (Fig. 3b).

Figure 4 shows the deposition of rhodamine 123 in the vegetative regions of $S$. japonica sporophytes with no wound. The green fluorescence of rhodamine 123 was observed in the apoplast of the outer cortical cells and the cuticle layers in the vegetative region of sporophytes (Fig. 4a, b). Small wounded sites also exhibited green fluorescence (Fig. 4c). Strong rhodamine 123 fluorescence was also observed in the wounded region of the sporophyte disc (Fig. 5a). The fluorescence was distributed throughout the wound. Moreover, strong rhodamine 123 fluorescence was distributed throughout sori (Fig. 5b, c). In contrast, the
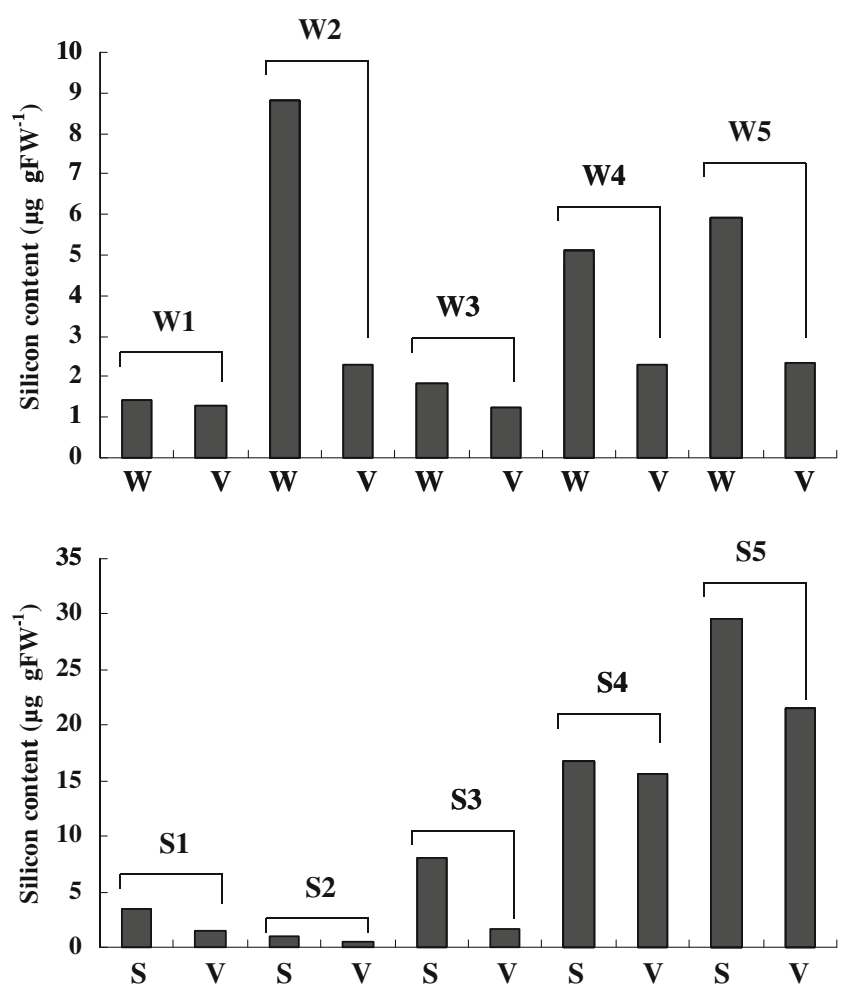

Fig. 2 Comparison of the silicon content of scars with a hole $(w)$ and the adjacent regions with no wound $(V)$ and between the sorus $(s)$ and adjacent non-sorus portions (v) in Saccharina japonica sporophytes. Numbers in the figure indicate the scar and sorus numbers

red fluorescence of chlorophyll dominated the vegetative regions. In sori, green fluorescence was particularly noticeable in the mucilage caps and the paraphyses (Fig. 5d).

\section{Discussion}

Silicon deposition in wounded tissues of S. japonica sporophytes Kelp is continuously exposed to the stress of
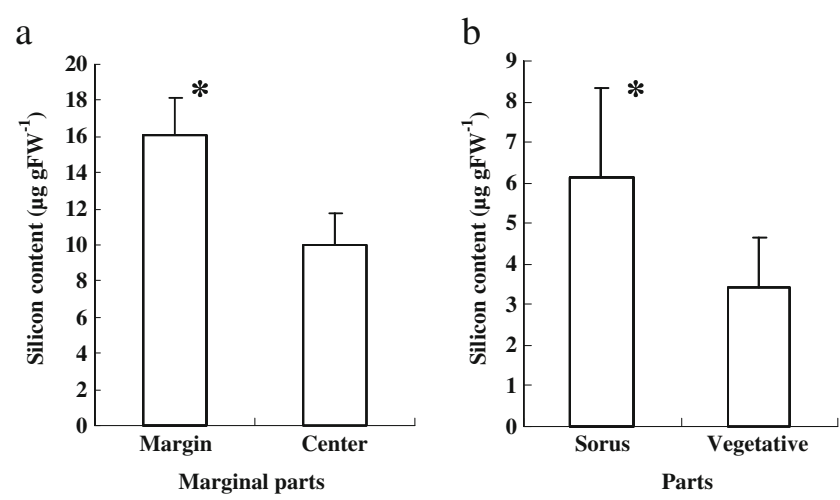

Fig. 3 Comparison of silicon content in the marginal and central regions of Saccharina japonica sporophyte discs cultured for 1 month (a) and between sori and the adjacent regions (b). Asterisks indicate a significant difference at $P<0.01$ 


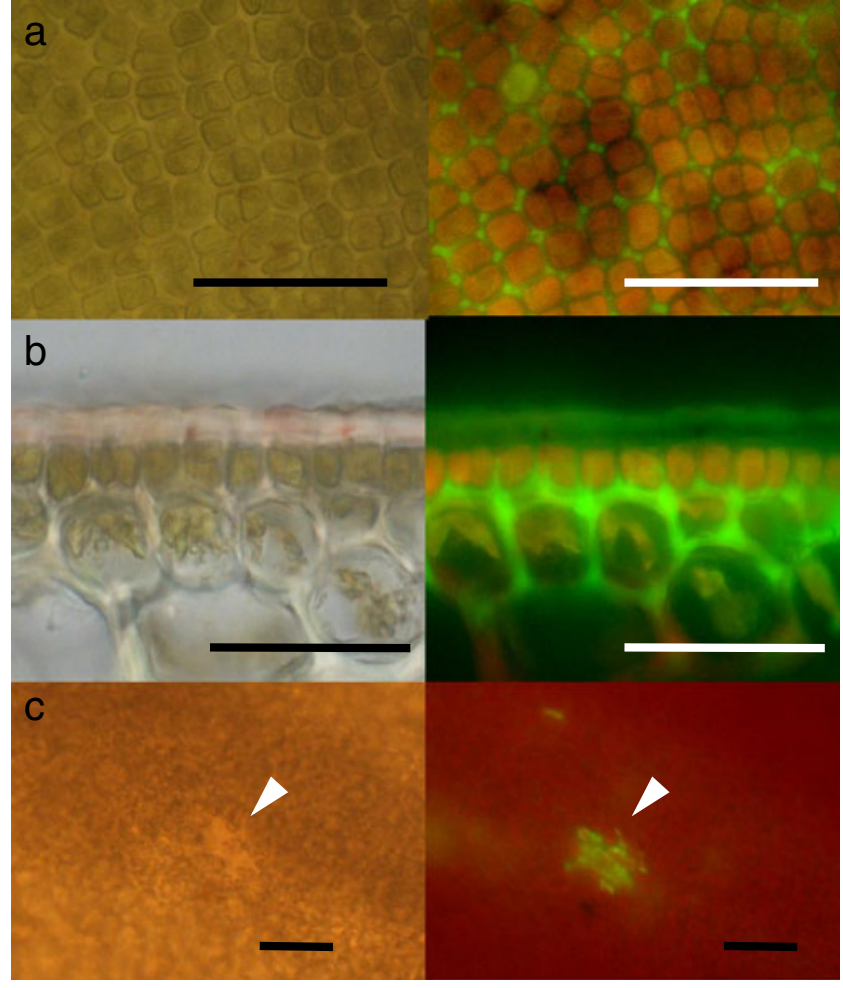

Fig. 4 Bright field (left) and fluorescence (right) images of the vegetative region of Saccharina japonica sporophyte discs loaded with rhodamine 123. a Surface view of the vegetative region, showing the distribution of rhodamine 123 fluorescence in the interstitial area between cells. b Sectional view of the vegetative region, showing the fluorescence distributed in the cuticle, but mainly in the apoplast between the epidermal cells and outer cortical cells. c Surface view of the vegetative region with a small wounded region (arrows). Scale bars: $50 \mu \mathrm{m}$ in (a) and (b) and $100 \mu \mathrm{m}$ in (c)

being wounded by physical damage and grazing in natural environments. Wounding is known to affect the growth and survival of kelps (DeWreede et al. 1992) and fucoids (Toh and Pavia 2006). Wounding increases the susceptibility to pathogen attack, and the timing and level of wounding also influences the quality and quantity of production of industrial seaweeds. Plants generally possess constitutive resistance that is mediated via morphological and chemical systems. The cuticle forms the outermost boundary of the thallus between the internal and external environments, and it provides a protein-rich barrier that confers constitutive resistance (Hanic and Craigie 1969). Sulfated polysaccharides predominate in the cuticle, outer cortex and mucilage ducts (Parker and Diboll 1966), where they provide effective protection against stress (De Lestang and Quillet 1981). Interestingly, silicon was distributed in the cuticle and mucilage caps of sori. It was also deposited in the wounded tissues and in the apoplast between the epidermal cells and outer cortical cells of the vegetative tissues. These observations suggest that silicon contributes to protection from biological attacks and the healing of the wounded

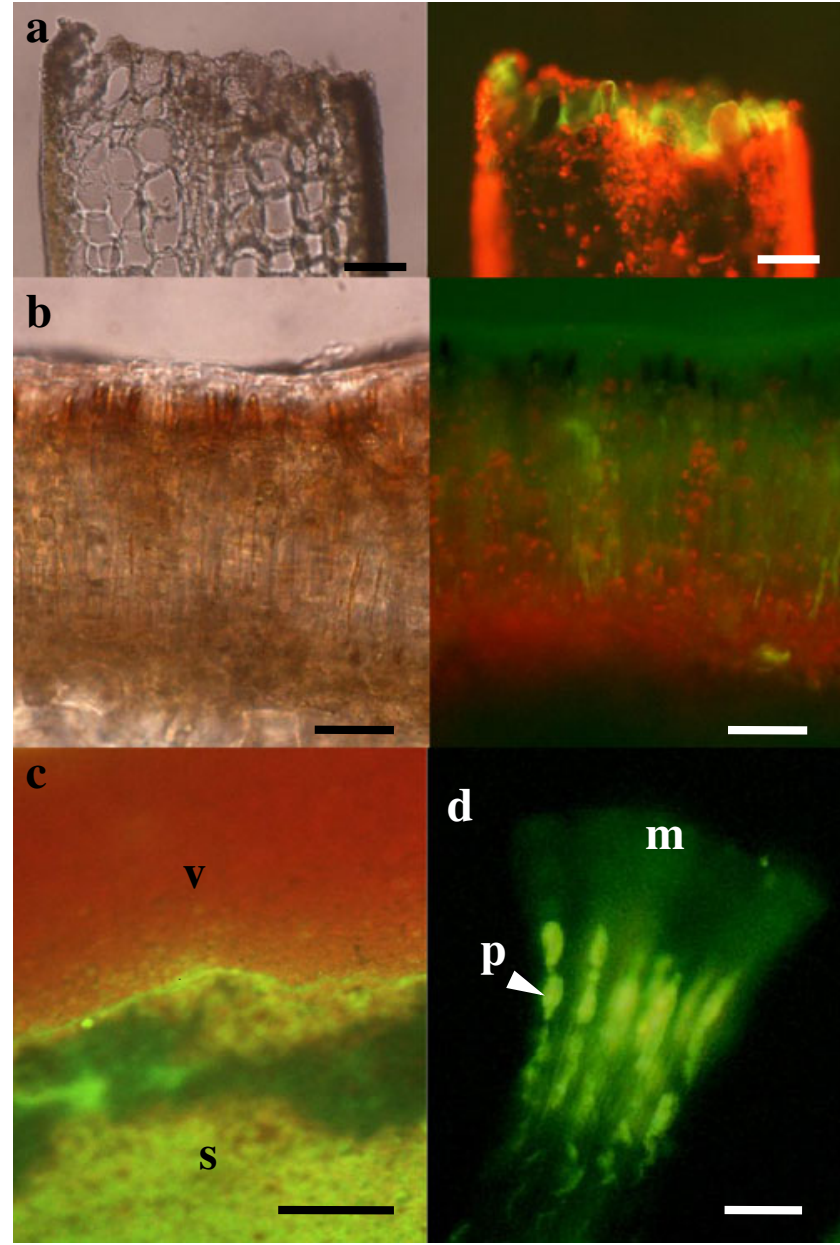

Fig. 5 Bright field (left) and fluorescence (right) images of a wound (a) and sorus (b) in Saccharina japonica sporophyte discs loaded with rhodamine 123. (c) Fluorescent surface view image of a transitional area between the sorus $(s)$ and non-sorus $(V)$ portions, showing strong green fluorescence of rhodamine 123 in the sorus and red fluorescence of chlorophyll in the non-sorus portions. (d) Microscopic fluorescence image of separated paraphyses $(p)$ with mucilaginous caps $(m)$, showing the distribution of fluorescence in paraphyses and mucilaginous caps. Scale bars $50 \mu \mathrm{m}$ in (a), (b), $100 \mu \mathrm{m}$ in (c) and $10 \mu \mathrm{m}$ in $(\mathbf{d})$

regions, while wound expansion is prevented by protectants such as sulfated polysaccharides. This suggests that silicon plays an important role in constitutive resistance.

Schwarz (1973) reported that silicon may function as a biological cross-linking agent that contributes to the architecture and resilience of the connective tissues, because large amounts of bound silicon are present in pectin and alginic acid. Alginic acid is the major matrix component in brown algae and is distributed in the immediate cell wall (Kloareg and Quatrano 1988). The deposition of silicon is probably closely associated with its binding to apoplastic components such as alginic acid. Furthermore, the toughness of scars seems to be closely linked to the high silicon content of the wounded tissues, 
although its deposition mechanism remains a subject of future research.

Longitudinal and transverse silicon distribution throughout $S$. japonica thallus The transverse distribution of silicon was lower in the basal meristem and higher in the older parts, suggesting that silicon was not necessarily required for sporophyte elongation. The marginal regions also had a higher silicon content compared to the median fasciae. In particular, silicon was accumulated at the edge of the marginal region. This was considered to be related to the high silicon content in the wounded tissues. The thalli of $S$. japonica sporophytes have a thick median fascia that occupies one third of the width, with relatively thin marginal regions on both sides of the median fascia. The marginal regions are considered to be weak compared to the median fascia and they are continually exposed to physical damage. The marginal regions play an important role in photosynthesis and nutrient uptakes, and the changes in width with morphological form and the undulating levels are suggested to be a response to environmental conditions (reviewed by Hurd 1997). Therefore, the marginal region needs to compensate for the weakness caused by its thickness. Thus, silicon may be deposited to protect from the trauma of wounding. From this perspective, silicon provides excellent constitutive resistance in the marginal regions than in the thick median fascia that has less need for strengthening.

Contribution of silicon in the protection of S. japonica sporophyte reproductive tissues Kelp sporophytes possess mechanisms for protecting their reproductive organs in sori. The sorus is composed of zoosporangia, paraphyses and mucilage caps. The paraphyses and mucilaginous caps provide a protective covering for the developing sori (Fritsch 1952). The mucilage cup is believed to be composed of a sulfated polysaccharide (Motomura 1993). It has also been suggested that sori have a high phenolic compound content and that they are protected by the release of iodine and radical oxygen species to combat biotic stresses (Mizuta and Yasui 2010). Silicon deposition is also considered to provide constitutive resistance in kelp sori, particularly in the paraphyses and mucilage caps. This current study suggests that silicon deposition might contribute to the success of kelp reproduction.

Induced resistance has also been reported in seaweeds (reviewed by Dring 2006), where mechanical wounding induces an oxidative burst (Collén and Pedersen 1994; Ross et al. 2005). Callus formation after cutting sporophyte segments also induces an oxidative burst (Kanamori et al. 2011). Phlorotannin plays an important role as an antiherbivory agent; it is also involved in the wound-healing process of seaweeds (Hammerstrom et al. 1998). Silicon deposition appears to progress with induced resistance, suggesting that wound healing and kelp reproduction are supported by both constitutive and induced resistance mechanisms. However, the relationship of silicon deposition and oxidative burst was not elucidated in our study.

Function and requirements for silicon deposition in $S$. japonica sporophytes The key mechanisms of siliconmediated alleviation of abiotic stresses in higher plants include: (1) stimulation of antioxidant systems in plants, (2) complexing or co-precipitation of toxic metal ions with silicon, (3) immobilisation of toxic metals in growth media, (4) uptake processes and (5) compartmentalization of metal ions in plants (Liang et al. 2007). In our study, silicon was found to play an important role in the protection of kelp body, suggesting that it is a quasi-essential element in kelp (Epstein 1999). This requirement is similar to that in higher plants although it remains doubtful whether silicon is a beneficial element.

Silicon was not previously considered to be an environmental factor that influences the cultivation, management and production of kelp in the field or kelp seedling production. However, we now need to consider that silicon might have a protectant role in the management of kelp cultivation. In addition, rhodamine 123 was useful for the evaluation of wounding levels during the cultivation.

Acknowledgements This work was supported in part by a Grant-inAid for Scientific Research from the Japan Society for the promotion of Science (no. 22580195).

Open Access This article is distributed under the terms of the Creative Commons Attribution Noncommercial License which permits any noncommercial use, distribution, and reproduction in any medium, provided the original author(s) and source are credited.

\section{References}

Brezeinski M, Conley DJ (1994) Silicon deposition during the cell cycle of Thalassiosira weisflogii (Bacillariophyceae) determined using dual rhodamine 123 and propidium iodide staining. J Phycol 30:45-55

Collén J, Pedersen M (1994) A stress-induced oxidative burst in Eucheuma platycladum (Rhodophyta). Physiol Plantarum 92:417-422

Currie HA, Perry CC (2007) Silica in plants: biological, biochemical and chemical studies. Ann Bot 100:1383-1389

De Lestang G, Quillet M (1981) The sulfated fucoidan of Phaeophyceae as a factor of biological adaption. Proc of $8^{\text {th }}$ Int. Seaweed Symposium, pp 200-204

DeWreede RE, Ewanchuk P, Shaughnessy F (1992) Wounding, healing and survivorship in the three kelp species. Mar Ecol Prog Ser 82:259-266 
Dring MJ (2006) Stress resistance and disease resistance in seaweeds: the role of reactive oxygen metabolism. Adv Bot Res 43:175-207

Epstein E (1999) Silicon. Annu Rev Plant Physiol Plant Mol Biol 50:641-644

Fritsch FE (1952) The structure and reproduction of the algae. Vol.2 Foreword, Phaeophyceae, Rhodophyceae, Myxophyceae. Cambridge Univ Press 939p

Fu F-F, Akagi T, Yabuki S, Iwaki M, Ogura N (2000) Distribution of rare earth elements in seaweed: implication of two different sources of rare earth elements and silicon in seaweed. J Phycol 36:62-70

Hammerstrom K, Dethier MN, Duggins DO (1998) Rapid phlorotannin induction and relaxation in five Washington kelps. Mar Ecol Prog Ser 165:293-305

Hanic LA, Craigie JS (1969) Studies on the algal cuticle. J Phycol 5:89-102

Hurd CL (1997) Water motion, marine macroalgal physiology, and production. J Phycol 36:453-472

Kanamori M, Mizuta H, Yasui H (2011) Effects of ambient calcium concentration on morphological form of callus-like cells in Saccharina japonica (Phaeophyceae) sporophyte. J Appl Phycol. doi:10.1007/s10811-011-9688-x

Kloareg B, Quatrano RS (1988) Structure of the cell walls of marine algae and ecophysiological functions of the matrix polysaccharides. Oceanogr Mar Biol Ann Rev 26:259-315

Kohata S, Sumi T, Tanemura K, Sakamoto T, Zhimoda M, Asakawa M (2008) Characterization and enzymatic digestion of seaweed cultured in the Yatsushiro Sea. J Tech Educ 15:1-10 (in Japanese with English abstract)

Lewin J, Reimann EF (1966) Silicon and plant growth. Annu Rev Plant Physiol 20:289-304

Li C-W, Chu S, Lee M (1989) Characterizing the silica deposition vesicle of diatoms. Protoplasma 151:158-163

Liang Y, Sun W, Zhu Y, Christe P (2007) Mechanisms of siliconmediated alleviation of abiotic stress in higher plants: a review. Environ Pollut 147:422-428

Markham JW, Hagmeier E (1982) Observations on the effects of germanium dioxide on the growth of macro-algae and diatoms. Phycologia 21:125-130

McLachlan J, Chen LC, Edelstein T (1971) The culture of four species of Fucus under laboratory conditions. Can J Bot 49:1463-1469

Mizuta H, Yasui H (2010) Significance of radical oxygen production in sorus development and zoospore germination in Saccharina japonica (Phaeophyceae). Bot Mar 53:409-416
Moore LF, Traquair JA (1976) Silicon, a required nutrient for Chladophora glomerata (L) Kütz. (Chlorophyta). Planta 128:179-182

Motomura T (1993) Ultrastructural and immnofluorescence studies on zoosporogenesis in Laminaria angustata. Sci Pap Inst Alg Res Hokkaido Univ 9:1-32

Müller WEG, Rothenberger M, Boreiko A, Tremel W, Reiber A, Schröder HC (2005) Formation fo siliceous spicules in the marine demosponge Suberites domuncula. Cell Tiss Res 321:285-297

Müller WEG, Engel S, Wang X, Wolf SE, Tremel W, Thakur NL, Krasko A, Divekar M, Schröder HC (2008) Bioencapsulatio of living bacteria (Escherichia coli) with poly(silicate) after transformation with silicatein- $\alpha$ gene. Biomaterials 29:771-779

Parker BC (1969) Occurrence of silica in brown and green algae. Can J Bot 47:537-539

Parker BC, Diboll AG (1966) Alcian stains for histochemical localization of acid and sulfated polysaccharides in algae. Phycologia 6:37-46

Parsons TR, Maita Y, Lalli CM (1984) A manual of chemical and biological methods for seawater analysis. Pergamon Press, Oxford, 173p

Provasoli L (1968) Media and prospects for the cultivation of marine algae. Culture and collections of algae. Proceeding US-Japan Conference Hakone, September 1968. Japanese Society of Plant Physiology, Tokyo, pp. 63-75

Ross C, Küpper FC, Vreeland V, Wite JH, Jacobs RS (2005) Evidence of a latent oxidative burst in relation to wound repair in the giant unicellular chlorophyte Dasycladus vermicularis. J Phycol 41:531-541

Schwarz K (1973) A bound form of silicon in glycosaminoglycans and polyuronides. Proc Nat Acad Sci USA 7:1608-1612

Shea R, Chopin T (2007) Effects of germanium dioxide, an inhibitor of diatom growth, on the microscopic laboratory cultivation stage of the kelp, Laminaria saccharina. J Appl Phycol 19:27-32

Tatewaki M, Mizuno M (1979) Growht inhibition by germanium dioxide in various algae, especially in brown algae. Jap J Phycol 27:205-212 (in Japanese with English abstract)

Toh GB, Pavia H (2006) Artificial wounding decrease plant biomass and shoot strength of the brown seaweed Ascophyllum nodosum (Fucales, Phaeophyceae). Mar Biol 148:1193-1199

Yoshida S, Ohnishi Y, Kitagishi K (1962) Histochemistry of silicon in rice plant III. The presence of cuticle-silica double layer in the epidermal tissue. Soil Sci Plant Nutr 8:1-5 